\title{
Lessons Learned from Introducing the Characteristic of an Outstanding Medical Teacher: Its Implication in Role Modeling and Professionalism
}

\section{Soleiman Ahmady}

Shaheed Beheshti University of Medical Sciences

Hamidreza Namazi

Tehran University of Medical Sciences

Alireza Monajemi

Institute of Humanities and Cultural Studies

Noushin Kohan ( $\square$ nu.kohan@gmail.com )

Virtual University of medical education https://orcid.org/0000-0002-8163-742X

Research article

Keywords: Role Modeling, Professionalism, Conceptual Framework, Medical Teacher

Posted Date: May 22nd, 2020

DOI: https://doi.org/10.21203/rs.3.rs-28398/v1

License: (c) (1) This work is licensed under a Creative Commons Attribution 4.0 International License.

Read Full License 


\section{Abstract}

Background Role models play a crucial role in determining the professional development of medical trainees. The purpose of this qualitative descriptive study is to gain in-depth understanding of the outstanding qualities of one successful role model in Iran. We described his character, personality and merits as a conceptual framework for role modeling in medical education.

Methods Qualitative descriptive study. Inductive content analysis was performed, and data were collected by conducting interviews. The study was done in the school of medicine of Tehran University of Medical Sciences in Iran. Twenty five medical students, medical graduates and faculty members participated in 25 interviews from April to December 2019. The participants were recruited via purposive sampling.

Results Five themes, 13 subthemes, and 46 categories were extracted from the data, and the conceptual framework of role modeling in medical education was developed.

Conclusion In this study, we designed a framework for role modeling in medical education Based on this framework, role models in medical education can function as mentors, medical leaders, clinical teachers, and professional instructors. Overall, role modeling is an important concept in medical education, and results of this article contributes to maintain the high quality of medical education.

\section{Background}

Although professionalism is an essential competency for physicians, it can be challenging for instructors to teach and cultivate it [1]. In this regard, a systematic review identified role modeling as one of the best approaches for cultivating professionalism in medical students [2]. Professional identity is also an emerging paradigm in professionalism, which provides a framework for assessing the influence of role models on medical students. This framework emphases on the progressive identity development of learners through involvement in a community of practice that holds to certain values and aspirations [3].

Improvement of professional identity and role modeling has become a major element in medical education reform [4]. Role modeling is a student-driven phenomenon in comparison with other learning methods, which may take place with or without the instructor's awareness [5]. Role modeling of positive or negative behaviors by physicians is an essential component of clinical teaching [6]. Generally, a role model is described as "a person considered to demonstrate a standard of excellence to be imitated... facilitating learning by observation" [7]. Role modeling has been also described as the process in which "faculty members demonstrate clinical skills, model, and articulate expertise thought processes and manifest positive professional characteristics" [8].

Generally, role models do not resemble mentors, as they are described as individuals who can inspire a sense of mission and teach by example. On the other hand, mentors are known to establish a formal communication with the students [9]. Effective role models have to be competent in clinical, personal, and teaching skills. Therefore, role modeling is a combination of individual characteristics ("Heart"), 
professional patient care ("Hands-on"), and making the implicit explicit in teaching medicine ("Head") [10].

According to our review of the literature, the most prominent theme in role modeling is that medical students learn from their role models. In a one study, $90 \%$ of medical graduates remembered their role models, who formed their professional attitude [11]. Moreover, in a recent Best Evidence Medical Education (BEME) study on doctors' role modeling in medical education, five main themes were extracted: characteristics of positive role models for physicians; personality type of positive role models; inspiring impact of positive role models on the students' future career choice; process of positive role modeling; and impact of negative role models [12]. In another study, the majority of medical students believed that observing their role models influenced their learning more than formal teaching [13].

In Iran, physicians comprise a community of professionals, affecting the health of the public. Therefore, educating medical students for practice in the changing medical environment is of great importance in medical schools. Since the beginning of a new era in Iranian medical education, professionalism has become a fundamental part of teaching and practicing medicine. In this approach, empirical research on professionalism has attracted major attention to role modeling, which can have a significant impact on the development of professional values and competencies of medical students. Some medical schools have also made attempts to nurture this important competency.

One of the famous role models in Iranian medicine is Prof. Alireza Yalda, who was born in 1930. He was accepted into Tehran University of Medical Sciences (TUMS) in 1951 and graduated the university in 1957. He became an infectious diseases specialist in 1960. After completing his internship, he was accepted as a faculty member of TUMS and gradually became a professor. His outstanding research on infectious diseases, great teaching abilities, and ethical behaviors towards patients, colleagues, medical staff, and students made him an unrivaled professor and a great example of excellent morals, humanity, and knowledge.

Prof. Yalda has been awarded over 20 scientific awards for outstanding scholarly and research activities. $\mathrm{He}$ is the first Iranian physician and professor to be awarded the "Sustain Faces". He is known as a pioneer, a role model, and a mentor, whose professional achievements are known to many.

The purpose of this qualitative descriptive study is to gain in-depth understanding of the outstanding qualities of successful role model that Prof. Yalda provided. We described his character, personality and merits as a role model in medical profession.

It is imperative that culture is considered by its impacts on choice of a medical role model. ${ }^{14}$ This paper explores role modeling concept as a way of reflecting upon and sharing diverse cultural experiences.

\section{Methods}


In this qualitative descriptive study, inductive content analysis was performed. Data were collected by conducting interviews. This research consisted of three stages. First, we conducted a literature review on the conceptual frameworks of role modeling. Second, we conducted qualitative interviews with faculty members and medical students about the attitude and behaviors of Prof. Yalda as a role model. Finally, in the third stage, a conceptual model was designed based on the previous steps.

\section{Literature review}

In the first stage, we conducted a literature review of the conceptual frameworks of role modeling. We searched the literature published in four databases (Web of Science, MEDLINE, Google Scholar, and Scopus) until May 2019, using the following keywords: "role modeling", "conceptual framework", "academic medicine", and "higher education". By searching the databases, a total of 35 articles were retrieved for review. Twelve studies were of limited relevance or completely irrelevant, 14 were majorly relevant, and nine included information on the conceptual frameworks of role modeling. Twenty-three articles were finally selected for the final review.

\section{Qualitative study}

\section{Setting}

The study setting was the School of Medicine of TUMS, which holds comprehensive medical programs, including residency (specialty and subspecialty), fellowship, and MD programs. It also holds different graduate programs in basic sciences (MSc, MPH, and PhD). Generally, faculty members are known as prominent clinicians and scholars not only for didactic training, but also for role-modeling, transfer of clinical skills, and research mentoring. The TUMS School of Medicine is committed to research excellence, ethics, and provision of clinical services, especially in demanding clinical scenarios. Prof. Yalda was a faculty member of the School of Medicine of TUMS.

\section{Recruitment process}

We invited 25 participants to this study (see below) from April to December 2018. The participants were recruited via purposive sampling for semi-structured interviews. E-mail invitations for participation in the study described the purpose of the study. None of the contacted candidates refused to participate in the study, but the final appointment was based on the individual's availability on specific dates. The participants were recruited from TUMS.

\section{Data collection}

Semi-structured interviews were conducted for data collection in order to allow the participants to describe their experiences freely. The interviews started with a general question about the individual's perception of Prof. Yalda as a role model. Some probing questions, such as "How do you define a great role model?" were also asked. The probing questions were based on the participants' answers to the 
general questions. The interviewer encouraged the participants to provide more explanations about the issues.

The participants were also invited to talk about issues, which were not discussed in the interviews. The interviews were conducted in a quiet room and recorded using a tape recorder. Each interview lasted between 35 and 65 minutes. The interviews were immediately transcribed and analyzed. Sampling and data collection continued until data saturation, based on the immediate analysis of data after transcribing the interviews. Data saturation was reached after coding and analyzing 25 interviews.

\section{Data analysis}

Qualitative content analysis, which provides valuable information about people's experiences and perceptions of a phenomenon, was performed to collect the data. We used inductive content analysis, defined by Elo and Kyngas (2008), for data analysis. Themes and categories were extracted from the transcribed texts via inductive content analysis, without considering previous theoretical frameworks. All interviews were recorded on videotapes and then audio-transcribed. The transcripts were analyzed by two of the authors of this manuscript, and an agreement was achieved with the research group. This process briefly included the following two stages: selection of the analysis unit and understanding the data in the preparation phase; and open coding, formation of categories, and abstraction in the organization phase.

Rigor

Peer-checking was performed in the data analysis phase by two peers for ensuring the credibility and trustworthiness of the data.

\section{Ethical considerations}

All of the participants were given information about the aims of the study. In addition, the participants were informed that they could withdraw from the study at any time. Written consents were also obtained from the participants. Moreover, permission was obtained for recording the interviews. Confidentiality was maintained in all steps of data collection and analysis.

\section{Results}

The study population included 8 (65\%) women and 17 (35\%) men. Eight participants were medical faculties, seven participant were medical graduate and ten were medical students. The participants' age ranged from 23 to 68 years (mean age: 45.5 years). Five themes, 13 subthemes, and 46 categories were extracted from the data, which are presented in Tables 1-5. The participant's quotes presented in Table 6. The conceptual framework is also demonstrated in Fig. 1. 
Table 1

Theme, subthemes and categories of an effective coach and mentor

\begin{tabular}{|c|c|c|}
\hline Theme & Subthemes & Categories \\
\hline \multirow[t]{13}{*}{$\begin{array}{l}\text { Prof. Yalda as an effective } \\
\text { coach and mentor }\end{array}$} & The perfect nurturer & $\begin{array}{l}\text { - Facilitating the achievement of } \\
\text { goals }\end{array}$ \\
\hline & & $\begin{array}{l}\text { - Advising medical students on } \\
\text { future career choices }\end{array}$ \\
\hline & & $\begin{array}{l}\text { - Coordinating professional } \\
\text { development }\end{array}$ \\
\hline & & $\begin{array}{l}\text { - Providing positive and negative } \\
\text { feedback }\end{array}$ \\
\hline & & - A great reference source \\
\hline & $\begin{array}{l}\text { A strong facilitator and an } \\
\text { encourager }\end{array}$ & $\begin{array}{l}\text { - Encouraging student } \\
\text { participation }\end{array}$ \\
\hline & & - Encouraging teamwork \\
\hline & & - Encouraging reflection \\
\hline & & $\begin{array}{l}\text { - Promoting balance between } \\
\text { work and life }\end{array}$ \\
\hline & & $\begin{array}{l}\text { - Promoting intellectual and } \\
\text { emotional engagement }\end{array}$ \\
\hline & $\begin{array}{l}\text { A professional succession } \\
\text { planner and an advisor }\end{array}$ & $\begin{array}{l}\text { - Sharing knowledge and } \\
\text { experience }\end{array}$ \\
\hline & & - Caring about one's profession \\
\hline & & - Identifying talented people \\
\hline
\end{tabular}


Table 2

Theme, subthemes and categories of an inspiring medical leader

\begin{tabular}{|c|c|c|}
\hline Theme & Subthemes & Categories \\
\hline \multirow{10}{*}{$\begin{array}{l}\text { Prof. Yalda as an inspiring } \\
\text { medical leader }\end{array}$} & \multirow[t]{3}{*}{ Academic planner } & - Hidden leadership and management \\
\hline & & $\begin{array}{l}\text { - Management of the university } \\
\text { authorities }\end{array}$ \\
\hline & & $\begin{array}{l}\text { - Close observation of the academic } \\
\text { environment }\end{array}$ \\
\hline & \multirow[t]{4}{*}{$\begin{array}{l}\text { Supporter of academic } \\
\text { community }\end{array}$} & $\begin{array}{l}\text { - Supporting and encouraging top } \\
\text { academic leaders }\end{array}$ \\
\hline & & $\begin{array}{l}\text { - Presence in academic events and } \\
\text { ceremonies }\end{array}$ \\
\hline & & - Supporting university education \\
\hline & & $\begin{array}{l}\text { - Gaining the support of upper } \\
\text { management }\end{array}$ \\
\hline & \multirow{3}{*}{$\begin{array}{l}\text { An agent of effective } \\
\text { change }\end{array}$} & - Influencing the academic culture \\
\hline & & $\begin{array}{l}\text { - Influencing the values of academic } \\
\text { environment }\end{array}$ \\
\hline & & $\begin{array}{l}\text { - Guiding organizational vision and } \\
\text { mission }\end{array}$ \\
\hline
\end{tabular}


Table 3

Theme, subthemes and categories of an expert clinical teacher

\begin{tabular}{|c|c|c|}
\hline Theme & Subthemes & Categories \\
\hline \multirow{17}{*}{$\begin{array}{l}\text { Prof. Yalda as an expert } \\
\text { clinical teacher }\end{array}$} & \multirow{3}{*}{$\begin{array}{l}\text { Excellent } \\
\text { personality }\end{array}$} & - Patient and humble \\
\hline & & - Kind and caring \\
\hline & & - Honest and truthful \\
\hline & \multirow[t]{5}{*}{$\begin{array}{l}\text { Professional } \\
\text { patient care }\end{array}$} & $\begin{array}{l}\text { - Having empathy with patients and their } \\
\text { companions }\end{array}$ \\
\hline & & - Effective interactions with the peers \\
\hline & & - Passion for work \\
\hline & & - Playing a heroic role in difficult clinical situations \\
\hline & & - Respect for patient autonomy \\
\hline & \multirow{9}{*}{$\begin{array}{l}\text { Excellent } \\
\text { teaching }\end{array}$} & - Empathy with the learner \\
\hline & & - Being available \\
\hline & & $\begin{array}{l}\text { - Understanding the learner's needs and } \\
\text { commitment to their development }\end{array}$ \\
\hline & & - Creating an exciting learning environment \\
\hline & & - Commitment to evidence-based learning \\
\hline & & - Commitment to scientific progress \\
\hline & & $\begin{array}{l}\text { - Creating learning opportunities through positive } \\
\text { and negative experiences }\end{array}$ \\
\hline & & - Motivating and supporting student learning \\
\hline & & - Guiding and providing support in the clinical field \\
\hline
\end{tabular}


Table 4

Theme, subthemes and categories of a professional physician

\begin{tabular}{|c|c|c|}
\hline Theme & Subthemes & Categories \\
\hline \multirow{10}{*}{$\begin{array}{l}\text { Prof. Yalda as a professional } \\
\text { physician }\end{array}$} & \multirow{6}{*}{$\begin{array}{l}\text { Professional } \\
\text { behavior }\end{array}$} & - Loyal and reliable \\
\hline & & - Philanthropist \\
\hline & & - Compassionate \\
\hline & & -Wisely honest \\
\hline & & - Courageous \\
\hline & & - Truthful and sympathetic \\
\hline & \multirow{4}{*}{$\begin{array}{l}\text { Professional } \\
\text { teacher }\end{array}$} & - Having professional knowledge \\
\hline & & - Helping students socialize \\
\hline & & $\begin{array}{l}\text { - Promoting the autonomy of the } \\
\text { profession }\end{array}$ \\
\hline & & - Interprofessional education \\
\hline
\end{tabular}

Table 5

Theme, subthemes and categories of an undeniable role model

\begin{tabular}{|lll|}
\hline Theme & Subthemes & Categories \\
\hline $\begin{array}{l}\text { Prof. Yalda as an undeniable role } \\
\text { model }\end{array}$ & $\begin{array}{l}\text { Professional } \\
\text { aspects }\end{array}$ & $\cdot$ A good doctor \\
& $\cdot$ A good manager and leader \\
& $\cdot$ A compassionate teacher \\
& $\cdot$ Satisfactory performance \\
& $\cdot$ Professional self-efficacy \\
& $\cdot$ Professional socialization \\
& $\cdot$ Confidentiality \\
& Emotional & - Self-confidence \\
aspects & Encouraging career choices \\
& & - Motivating professional growth and \\
\end{tabular}




\begin{tabular}{|lll|}
\hline Themes & $\begin{array}{l}\text { Subthemes } \\
\begin{array}{l}\text { Role } \\
\text { model as } \\
\text { an } \\
\text { effective } \\
\text { coach and } \\
\text { mentor }\end{array}\end{array} \begin{array}{l}\text { The perfect } \\
\text { nurturer }\end{array}$ & $\begin{array}{l}\text { "Prof. Yalda said that he was very pleased to see that when faculty } \\
\text { members have a medical problem, they are inclined to visit younger } \\
\text { doctors. At that time, Dr. X was recognized as an experienced } \\
\text { cardiologist. Prof. Yalda pointed at this young expert and told him that }\end{array}$ \\
$\begin{array}{l}\text { his work was exceptional. He was glad to see that we could educate } \\
\text { the next generation to be remarkable future physicians." }\end{array}$
\end{tabular}

A strong facilitator and encourager

A professional succession planner and an advisor
"At that time, if I was feeling sick or tired on my way to Imam Khomeini Hospital, I would go to Prof. Yalda in the infectious ward and return to work with positive energy. Dr. Yalda kept me away from the challenges and conflicts of the day, and he was always relaxed. For example, if a sad incident happened, he would say that in difficult times, we should keep our head down until the problems are resolved. He was attentive to details and encouraged everyone to be patient."

"If we made a mistake, he would not humiliate us; this unfortunately happens in academic environments. However, he believed that there are no mistakes, and he loved everyone."

"Whenever I had a medical question, I would share it with him."

"In addition to teaching medical sciences, he taught us to practice medicine. What he taught us was about life and ethics. By providing examples, he tried to teach us how to practice medicine.

Role Academic model as structure an planner

inspiring medical leader
"He was always the role model in our university and other universities in the country. He emphasized on the establishment of an ethical relationship between physicians for having a healthy, coherent, and active medical community. The professor could do a lot of work. He also rested and visited his children abroad, but the university and education were always prioritized. The absence of such a great person is very difficult for me."

Supporter of academic community that officials often hear negative words and pay attention to mistakes. Nonetheless, he strongly supported university administrators. One of
"He was not interested in being an authority figure, because he believed his most prominent features was that he had a particular attitude towards university officials and always thanked the university and faculty officials."

"During my work years, I heard him greet and thank many people; this is very important for someone with an executive responsibility."

"He attended academic events and enjoyed watching the health staff work."

An agent of effective change
"He was the leader of change in every field. He was strongly supported by the university when some major change was taking place. The academic staff of universities not only should acquire academic degrees, but also should act accordingly in a real sense. He introduced a new perspective towards medical practice in TUMS and other universities. The sanctity of medicine was very important from the society's point of view."

"In his interactions with colleagues, students, and the health staff in the infectious ward, he did not boast his knowledge, and he was
Role model as an expert
Excellent personal character 
clinical teacher

exemplary in his humility and modesty. He was very kind to the students, and at the same time, he was very serious about his job."

"Prof. Yalda and many of his colleagues at the infectious diseases ward were very good examples for teaching medical ethics. I wish for the students to have such people as role models rather than having them only read about the ethics theoretically. Prof. Yalda always kept up with the sciences and education. He taught his students to listen and be patient. He didn't encourage angry or emotional reactions."

Professional patient care
"Whenever Prof. Yalda saw us, he told us to be happy. He asked us not to forget that a doctor should treat patients with respect and kindness. Every university professor in an academic setting determines the level of academic and student skills. Prof. Yalda did this by surveying the patients. He could remember all the people who came to the hospital's infectious ward. I can say that besides students and colleagues, patients and even hospital workers respected him. I don't recall seeing someone have a conflict with Prof. Yalda."

\section{Excellent} teaching

Professional aspects

Role model as an undeniable role model

"I was attending an event at the infectious diseases department for a morning report when I saw Prof. Yalda, who seemed to be a prominent the audience by making them laugh and kept them engaged. His clinical vision was also exceptional. Despite his advancing age, he followed and studied new articles. He was also a scholar, who always studied. Like first-year students, he read the Harrison's book many times from the beginning and summarized the important points. The Harrison's book was a very good book back then, and he knew how to attract the students' attention and win their hearts. Many professors have a high level of knowledge, but their words have no power. Prof. Yalda was an exceptional example in this respect."

"Fortunately, those who have contact with each other contribute to the behavioral model. We hope that in the next decade, these professors act as role models at universities, because it is one of the academic necessities. Prof. Yalda approached the students very kindly. He discussed ethical issues and taught scientific subjects better than figure. He was an exceptional teacher and spoke fondly. He entertained other professors. That's why after thirty years, his teachings still remain in our minds."

"One of the things that the professor always emphasized on was that we should not compare our job with other professions. If others expect to receive money for the services they provide, we should not expect them to treat our illness. Because as a doctor, you have great responsibilities, and you should not equal your position with other jobs, which have a more material nature. During this time, I used the professor's great advice on how to work, how to behave, and how to talk to people."

Emotional aspects
"I still feel a strong connection with him. I still keep the photo of my last moments with him on my cell phone. May God teach us physicians his medical ethics."

"All people who were associated with Prof. Yalda recalled his calmness, humility, and dignity. He believed that if we want to succeed in life, we should set aside our pride. By avoiding our instincts, we will be ready to rise up, learn, and evolve."

"No one will forget his unique personality, even now that he is gone; his teachings promote spirituality and kindness to people around us. In my 
opinion, being a human is not about being a physician, a scientist, or a physician. If Prof. Yalda was not a professor or a medical doctor, he would still be a great man. Although he would not be recognized in the medical community, he would still have a positive impact on the society and would be regarded as a valuable asset to the community."

Table 6

participant's quotes extracted from qualitative study in sample of subthemes

\section{Discussion}

The proposed framework in this study holistically combines all attributes of role modeling in the context of medical education. Therefore, it provides an important contribution to the theoretical recognition of role modeling research. Our framework in this research identified five main themes, including "role model as a mentor", "role model as a medical leader", "role model as an expert clinical teacher", "role model as a professional physician", and "role model as a undeniable physician". Based on our results, mentoring is used for guiding and facilitating a learner's, success planning and educational growth. Fowler and O'Gorman in 2019 introduced eight categories of mentoring function: learning facilitation; coaching; personal and emotional guidance; facilitation of career development; advocacy; strategies and systems advice; role modeling; and friendship [15].

The main domains of most mentoring functions are based on a Kram mentoring Theory, which recognized two mentoring function categories: career-related function and psychosocial function. Psychosocial functions, which develop self-confidence and self-esteem, include counseling, friendship, and role modeling. On the other hand, career-related function includes exposure, protection, and sponsorship [16]. The present findings are consistent with previous research, which showed that with positive role models as mentors, medical students can develop their skills, including professional attitudes and behaviors, and develop their identity as a physician [17-19].

Based on our results, a role model is a person who is looked up by other people and whose behaviors and success are copied. A study by Huang et al. (2014) revealed that in the Leader-Member Exchange Theory, leaders are aware of their reputation and work to maintain a positive one in line with the organizational values. They also develop strong relationships with their follower and invest in them. These relationships provide an opportunity for leaders to intentionally act as role models. By relating to others and continuing their communication, leaders help others in order to help themselves [20].

According to a study by Saxena (2014), transformational leaders are unique and flexible, take risks, and are tolerant of uncertainty. They are passionate and inspirational, using their influence to act as role models. In addition to their inspirational role, they show expertise in some technical skills, which can involve people and/or leadership [21]. Chan (2019) believed that leaders, with both expert knowledge and unique access, are accepted as experts in the professional setting. They develop supportive relationships that benefit others because they are willing to lend expertise, access, time, and energy, providing both professional and psychosocial support for others [22]. 
Based on our results, the clinical trainer, supervising the trainee in clinical practice, becomes a role model for the trainee. Therefore, the trainer's professional behavior can have a positive effect on the trainee, whereas unprofessional behavior may have negative effects. In a systematic review of the literature on attributes of the clinical trainer as a role model, various lists of attributes have been proposed to describe clinical role models. These attributes can be classified into teaching qualities, patient care qualities, and personal qualities. A good clinical trainer needs to be conscious of his/her function as a role model, since development of clinical training skills may be supported by increased awareness of role modeling behaviors [7]. According to some researchers, a clinical trainer as a role model should make his/her behaviors explicit to the trainees in order to increase their attention and motivate them [10].

Based on our results, there is an urgent need for positive role models in medical training. These role models are the most powerful in the formation of professional character. The role models effect the development of professionalism. Positive doctor role models influence behavior of medical student by demonstrating them 'how to act' professionally with patients and clinical staff. Positive role models also help the medical students cultivate their own 'professional role' in medical practice and influencing career choices. The professionals highlighted that role modelling is vital as many professional characteristics such as 'integrity' are challenging to teach [23]. Finally the role models are undeniable and persistent in their mind of medical graduate. Role models provide support, protection, reflectiveness, advising, approval, confirmation, and coaching to their medical graduate and can have a great influence on students' awareness of the excellence of their medical graduate experience.

The findings of this study are subject to one limitations. The results might not be generalizable to all settings; nonetheless, we studied some frameworks and models of role modeling in our literature review.

The Implication of this study is the necessity of appropriate discussion in medical society about role modeling and how we may ensure that the faculty members are empowered to reach their full potential. This study has shown what is needed to construct an effective role model for medical education. Recognizing the five elements of effective role modeling based on our framework allows medical teachers to produce powerful form of learning for medical students.

\section{Strengths And Limitations Of This Study}

- We analysed rich data from, in-depth qualitative interviews conducted among different target groups of participants who have diverse experience and knowledge (Students, faculties and managers).

- The study aimed to enhance understanding of role modeling in medical education to improve support for medical students and share good practice.

- The study contextualises existing evidence pointing to the characteristics of effective rolemodeling and generate a model for how integrate it into the curriculum of medical students, residents, in various domains, include patient care, teaching, communication, and professionalism.

- The study presents new and unique data on how role modeling can be considered as a key factor in medical education. 
- The limitations of the study include the purposeful sampling and focusing on just one university in Iran; caution should be taken when generalising the conclusions to other university of the country or other countries. However, a good level of data saturation was achieved.

\section{Conclusion}

This is the first qualitative study to demonstrate the role modeling framework for medical education. The result of this study show the necessity of organized education and arguments for consensus making in the field to assist medical educationist in reaching the best plan for role modeling in medical education.

\section{Abbreviations}

TUMS: Tehran University of Medical Sciences

\section{Declarations}

\section{Ethics Approval and Consent to Participate}

All participants were given information about the aims of the study. In addition, participants were informed that they could withdraw from the study at any time without any consequences. Written consent was obtained from all participants. Moreover, permission was obtained for recording interviews. Confidentiality was maintained through all steps of data collection and analysis. The research proposal was submitted to the IRB committee. The committee reviewed the proposal and decided that there was no involvement of human or animal factors in the research and, hence there was no need for ethical approval.

\section{Consent to publish}

Not applicable.

\section{Availability of data and materials}

Data are available upon reasonable request.

\section{Competing interests}

None declared.

\section{Funding}




\section{Authors' Contributions}

"SA", "NK", "HN" and "AM" conceptualised this study. "SA" and "NK" wrote the draft, and "SA", "HN" and "AM" supervised the manuscript. "SA", "NK", "HN" and "AM" analysed the data."SA", "HN" and "AM" inspected the quality of data. "SA", "NK", "HN" and "AM" managed the overall design of the study. All Authors read and approved the manuscript.

\section{Acknowledgements}

We thank all of the participants who contributed in this study through interviews.

\section{References}

1. Mueller PS. Teaching and assessing professionalism in medical learners and practicing physicians. Rambam Maimonides medical journal. 2015;6(2).

2. Birden $\mathrm{H}$, Glass N, Wilson I, Harrison M, Usherwood T, Nass D. Teaching professionalism in medical education: a Best Evidence Medical Education (BEME) systematic review. BEME Guide No. 25. Medical teacher. 2013;35(7):e1252-e66.

3. Irby DM, Hamstra SJ. Parting the clouds: three professionalism frameworks in medical education. Academic Medicine. 2016;91(12):1606-11.

4. Brown ME, Laughey W, Tiffin PA, Finn GM. Forging a new identity: a qualitative study exploring the experiences of UK-based physician associate students. BMJ open. 2020;10(1).

5. Cruess SR, Cruess RL, Steinert Y. Role modelling-making the most of a powerful teaching strategy. Bmj. 2008;336(7646):718-21.

6. Bazrafkan L, Hayat AA, Tabei SZ, Amirsalari L. Clinical teachers as positive and negative role models: an explanatory sequential mixed method design. Journal of Medical Ethics and History of Medicine. 2019.

7. Jochemsen-van der Leeuw HR, van Dijk N, van Etten-Jamaludin FS, Wieringa-de Waard M. The attributes of the clinical trainer as a role model: a systematic review. Academic Medicine. 2013;88(1):26-34.

8. Irby DM. Clinical teaching and the clinical teacher. Academic Medicine. 1986;61(9):35-45.

9. Ricer RE. Defining preceptor, mentor, and role model. Family medicine. 1998;30(5):328-.

10. Jochemsen-van der Leeuw HR, van Dijk N, Wieringa-de Waard M. Assessment of the clinical trainer as a role model: a Role Model Apperception Tool (RoMAT). Academic Medicine. 2014;89(4):671.

11. Wright S, Wong A, Newill C. The impact of role models on medical students. Journal of General Internal Medicine. 1997;12(1):53-6. 
12. Passi V, Johnson S, Peile E, Wright S, Hafferty F, Johnson N. Doctor role modelling in medical education: BEME Guide No. 27. Medical teacher. 2013;35(9):e1422-e36.

13. Glicken AD, Merenstein GB. Addressing the hidden curriculum: understanding educator professionalism. Medical teacher. 2007;29(1):54-7.

14. McLean M. Is culture important in the choice of role models? Experiences from a culturally diverse medical school. Medical Teacher. 2004;26(2):142-9.

15. Fowler JL, Fowler DS, O'Gorman JG. Worth the investment? An examination of the organisational outcomes of a formal structured mentoring program. Asia Pacific Journal of Human Resources. 2019.

16. Rogers D. A Correlational study: E-mentoring, perceptions of E-mentoring and the actual career advancement of women In educational leadership: City University of Seattle; 2020.

17. Carter TJ, Brock EL, Fulco FA, Garber AM, Hemrajani RH, Lee BB, et al. BUILDING PROFESSIONAL IDENTITIES BY LEARNING FROM MENTORS AND ROLE MODELS. Transformative Learning in Healthcare and Helping Professions Education: Building Resilient Professional Identities. 2019:111.

18. Haque W, Gurney T, Reed WG, North CS, Pollio DE, Pollio EW, et al. Key Attributes of a Medical Learning Community Mentor at One Medical School. Medical Science Educator. 2019;29(3):721-30.

19. Clarke AJ, Burgess A, van Diggele C, Mellis C. The role of reverse mentoring in medical education: current insights. Advances in medical education and practice. 2019;10:693.

20. Huang J, Wang L, Xie J. Leader-member exchange and organizational citizenship behavior: The roles of identification with leader and leader's reputation. Social Behavior and Personality: an international journal. 2014;42(10):1699-711.

21. Saxena S. Are Transformational leaders creative and Creative leaders transformational? An attempted synthesis through the Big Five Factor Model of Personality Lens. Aweshkar Research Journal. 2014;18(2).

22. Chan SC. Participative leadership and job satisfaction. Leadership \& Organization Development Journal. 2019.

23. Passi V, Johnson N. The impact of positive doctor role modeling. Medical teacher. 2016;38(11):113945.

\section{Figures}




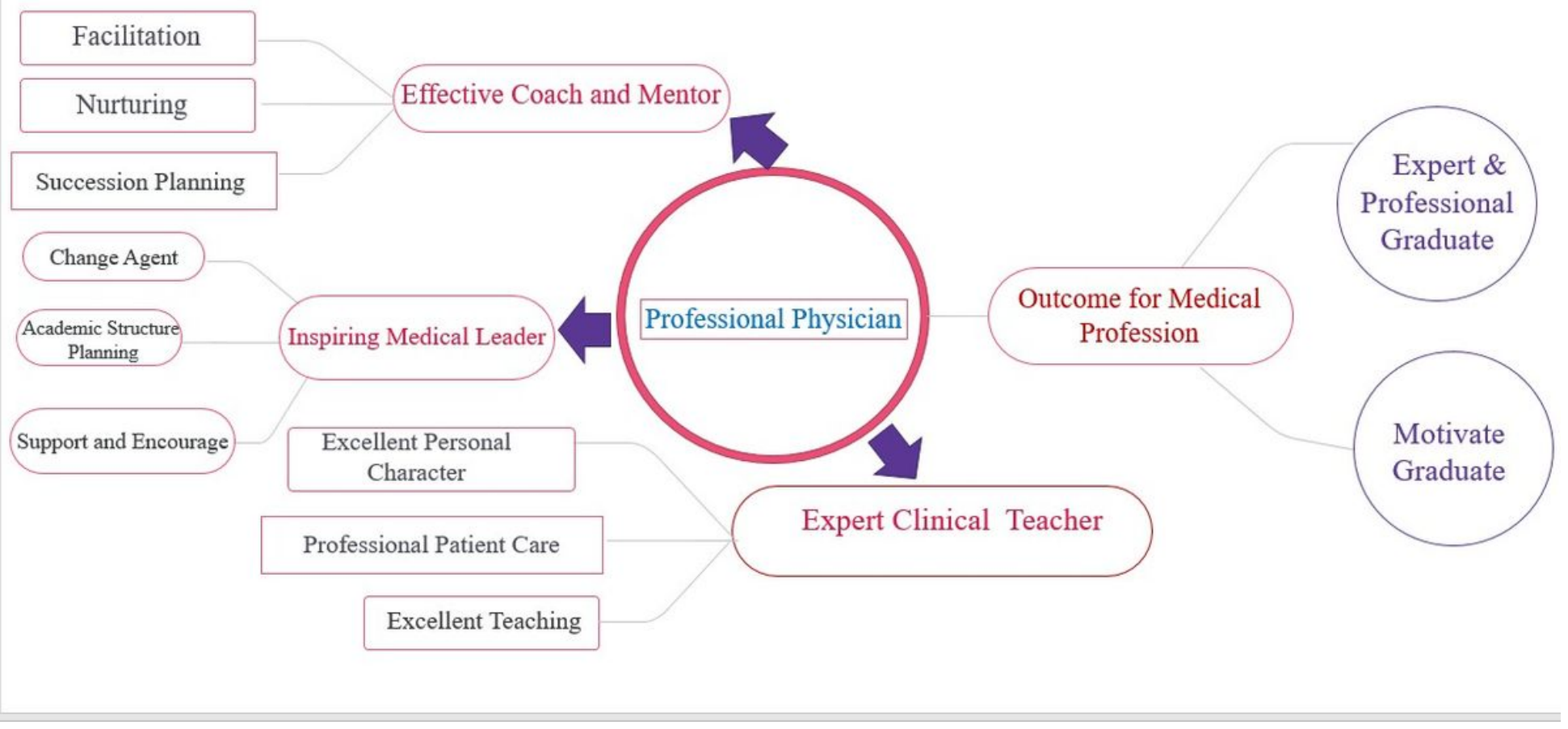

Figure 1

Conceptual Framework for Role Modeling in Medical Education 